\title{
Egocentric Biases in Availability and Attribution
}

\author{
Michael Ross and Fiore Sicoly \\ University of Waterloo, Waterloo, Canada
}

\begin{abstract}
Five experiments were conducted to assess biases in availability of information in memory and attributions of responsibility for the actions and decisions that occurred during a previous group interaction. The subject populations sampled included naturally occurring discussion groups, married couples, basketball teams, and groups assembled in the laboratory. The data provided consistent evidence for egocentric biases in availability and attribution: One's own contributions to a joint product were more readily available, that is, more frequently and easily recalled; individuals accepted more responsibility for a group product than other participants attributed to them. In addition, statements attributed to the self were recalled more accurately and the availability bias was attenuated, though not eliminated, when the group product was negatively evaluated (Experiment 2). Finally, when another participant's contributions were made more available to the individual via a selective retrieval process, the individual allocated correspondingly more responsibility for the group decisions to the coparticipant (Experiment 5). The determinants and pervasiveness of the egocentric biases are considered.
\end{abstract}

One instance of a phenomenon examined in the present experiments is familiar to almost anyone who has conducted joint research. Consider the following: You have worked on a research project with another person, and the question arises as to who should be "first author" (i.e., who contributed more to the final product?). Often, it seems that both of you feel entirely justified in claiming that honor. Moreover, since you are convinced that your view of reality must be shared by your colleague (there being only one reality), you assume that the other person is attempting to take advantage of you. Sometimes such concerns are settled or prevented by the use of arbitrary decision rules, for example, the rule of "alphabetical priority"-

This research was supported by a Canada Council grant to the first author. We are grateful to the following people for their comments on earlier versions of this article: Dick Bootzin, Leslie McArthur, Hildy Ross, Lee Ross, Shelley Taylor, Amos Tversky, and Mark Zanna. We thank Vicky Vetere for collecting the data in Experiment 5.

Requests for reprints should be sent to Michael Ross, Department of Psychology, University of Waterloo, Waterloo, Ontario, Canada N2L 3G1. a favorite gambit of those whose surnames begin with letters in the first part of the alphabet.

We suggest, then, that individuals tend to accept more responsibility for a joint product than other contributors attribute to them. It is further proposed that this is a pervasive phenomenon when responsibility for a joint venture is allocated by the participants. In many common endeavors, however, the participants are unaware of their divergent views, since there is no need to assign "authorship"; consequently, the ubiquity of the phenomenon is not readily apparent. The purpose of the current research was to assess whether these egocentric perceptions do occur in a variety of settings and to examine associated psychological processes.

In exploring the bases of such differential perceptions, we are not so naive as to suggest that intentional self-aggrandisement never occurs. Nonetheless, it is likely that perceptions can be at variance in the absence of deliberate deceit; it is from this perspective that we approach the issue.

To allocate responsibility for a joint endeavor, well-intentioned participants presum- 
ably attempt to recall the contributions each made to the final product. Some aspects of the interaction may be recalled more readily, or be more available, than others, however. In addition, the features that are recalled easily may not be a random subset of the whole. Specifically, a person may recall a greater proportion of his or her own contributions than would other participants.

An egocentric bias in availability of information in memory, in turn, could produce biased attributions of responsibility for a joint product. As Tversky and Kahneman (1973) have demonstrated, people use availability, that is, "the ease with which relevant instances come to mind" (p. 209), as a basis for estimating frequency. Thus, if self-generated inputs were indeed more available, individuals would be likely to claim more responsibility for a joint product than other participants would attribute to them.

There are at least four processes that may be operating to increase the availability of one's own contributions: (a) selective encoding and storage of information, (b) differential retrieval, (c) informational disparities, and (d) motivational influences.

\section{Selective Encoding and Storage}

For a number of reasons, the availability of the person's own inputs may be facilitated by differential encoding and storage of selfgenerated responses. First, individuals' own thoughts (about what they are going to say next, daydreams, etc.) or actions may distract their attention from the contributions of others. Second, individuals may rehearse or repeat their own ideas or actions; for example, they might think out their position before verbalizing and defending it. Consequently, their own inputs may receive more "study time," and degree of retention is strongly related to study time (Carver, 1972). Third, individuals' contributions are likely to fit more readily into their own cognitive schema, that is, their unique conception of the problem based on past experience, values, and so forth. Contributions that fit into such preexisting schemata are more likely to be retained (Bartlett, 1932; Bruner, 1961).

\section{Differential Retrieval}

The availability bias could also be produced by the selective retrieval of information from memory. In allocating responsibility for a joint outcome, the essential question from each participant's point of view may be, "How much did I contribute?" Participants may, therefore, attempt to recall principally their own contributions and inappropriately use the information so retrieved to estimate their relative contributions, a judgment that cannot properly be made without a consideration of the inputs of others as well.

\section{Informational Disparities}

There are likely to be differences in the information available to the contributors that could promote egocentric recall. Individuals have greater access to their own internal states, thoughts, and strategies than do observers. Moreover, participants in a common endeavor may differ in their knowledge of the frequency and significance of each other's independent contributions. For example, faculty supervisors may be less aware than their student colleagues of the amount of time, effort, or ingenuity that students invest in running subjects, performing data analyses, and writing preliminary drafts of a paper. On the other hand, supervisors are more cognizant of the amount and of the importance of the thought, reading, and so on that they put into the study before the students' involvement begins.

\section{Motivational Infuences}

Motivational factors may also mediate an egocentric bias in availability. One's sense of self-esteem may be enhanced by focusing on, or weighting more heavily, one's own inputs. Similarly, a concern for personal efficacy or control (see deCharms, 1968; White, 1959) could lead individuals to dwell on their own contributions to a joint product.

The preceding discussion outlines a number of processes that may be operating to render one's own inputs more available (and more likely to be recalled) than the contributions of others. Consequently, it may be dif- 
ficult to imagine a disconfirmation of the hypothesis that memories and attributions are egocentric. As Greenwald (Note 1) has observed, however, the egocentric character of memory "is not a necessary truth. It is possible, for example, to conceive of an organization of past experience that is more like that of some reference work, such as a history text, or the index of a thesaurus" (p. 4). In addition, we were unable to find published data directly supportive of the hypothesized bias in availability. Finally, recent developments in the actor-observer literature seem inconsistent with the hypothesis that memories and attributions are egocentric. Jones and Nisbett (1971) speculated that actors are disposed to locate the cause of their behavior in the environment, whereas observers attribute the same behavior to stable traits possessed by the actors. Though a variety of explanations were advanced to account for this effect (Jones \& Nisbett, 1971), the recent emphasis has been on perceptual information processing (Storms, 1973; Taylor $\&$ Fiske, 1975). The actor's visual receptors are aimed toward the environment; an observer may focus directly on the actor. Thus, divergent aspects of the situation are salient to actors and observers, a disparity that is reflected in their causal attributions. This proposal seems to contradict the thesis that actors in an interaction are largely self-absorbed.

Two studies offer suggestive evidence for the present hypothesis. Rogers, Kuiper, and Kirker (1977) showed that trait adjectives were recalled more readily when subjects had been required to make a judgment about self-relevance (to decide whether each trait was descriptive of them) rather than about a number of other dimensions (e.g., synonymity judgments). These data imply that self-relevance increases availability; however, Rogers et al. did not contrast recall of adjectives relevant to the self with recall of adjectives relevant to other people-a comparison that would be more pertinent to the current discussion. Greenwald and Albert (1968) found that individuals recalled their own arguments on an attitude issue more accurately than the written arguments of other subjects. Since the arguments of self and other were always on opposite sides of the issue, the Greenwald and Albert finding could conceivably reflect increased familiarity with, and memory for, arguments consistent with one's own attitude position rather than enhanced memory for self-generated statements (although the evidence for attitude-biased learning is equivocal, e.g., Greenwald \& Sakumura, 1967; Malpass, 1969).

We conducted a pilot study to determine whether we could obtain support for the hypothesized bias in availability. Students in an undergraduate seminar were asked to estimate the number of minutes each member of the seminar had spoken during the immediately preceding class period. An additional 26 subjects were obtained from naturally occurring two-person groups approached in cafeterias and lounges. The participants in these groups were asked to estimate the percentage of the total time each person had spoken during the current interaction.

It was assumed that subjects would base their time estimates on those portions of the conversation they could recall readily. Thus, if there is a bias in the direction of better recall of one's own statements, individuals' estimates of the amount of time they themselves spoke should exceed the average speaking time attributed to them by the other member (s) of the group.

The results were consistent with this reasoning. For seven of the eight students in the undergraduate seminar, assessments of their own discussion time exceeded the average time estimate attributed to them by the other participants $(p<.05$, sign test). Similarly, in 10 of the 13 dyads, estimates of one's own discussion time exceeded that provided by the other participant $(p<.05$, sign test). The magnitude of the bias was highly significant over the 13 dyads, $F(1,12)=14.85, p<$ .005 ; on the average, participants estimated that they spoke $59 \%$ of the time. These data provide preliminary, albeit indirect, evidence for the hypothesized availability bias in everyday situations.

The principle objectives of the current research were (a) to assess the ocurrence of egocentric biases in availability and attributions of responsibility in different settings; (b) 
to examine factors that were hypothesized to influence these biases; and (c) to offer preliminary evidence of a relation between a bias in availability and a bias in attributions of responsibility. Experiment 1 assessed the occurrence of egocentric biases in availability and allocations of responsibility in a natural setting and examined the relation between the two biases. Next, a laboratory experiment was conducted to address the issue of whether the quality of the group's performance affects the availability bias: Is the tendency for one's own inputs to be more available reduced substantially when the group's performance is poor, as a motivational interpretation would suggest? Experiment 3 further examined the effects of success and failure in a natural setting. The experimental manipulations in Experiments 4 and 5 were designed to influence availability, and changes in attributions of responsibility were assessed. The manipulation in Experiment 4 induced differential encoding; the manipulation in Experiment 5 varied the retrieval cues provided to the subjects.

\section{Experiment 1}

In this experiment, we wished to examine egocentric biases in naturally occurring, continuing relationships. Married couples appeared to represent an ideal target group. Spouses engage in many joint endeavors of varying importance. This circumstance would appear to be rife with possibilities for egocentric biases.

Accordingly, the first experiment was conducted (a) to determine if egocentric biases in allocations of responsibility occur in marital relationships; (b) to replicate, using a different dependent measure, the egocentric bias in availability obtained in the pretest; and (c) to correlate the bias in availability with the bias in responsibility. If the bias in responsibility is caused by a bias in availability, the two sets of data should be related.

\section{Method}

\section{Subjects}

The subjects were 37 married couples living in student residences. Twenty of the couples had children. The subjects were recruited by two female research assistants who knocked on doors in the residences and briefly described the experiment. If the couple were willing to participate, an appointment was made. The study was conducted in the couple's apartment; each couple was paid $\$ 5$ for participating.

\section{Procedure}

A questionnaire was developed on the basis of extensive preliminary interviews with six married couples. In the experiment proper, the questionnaire was completed individually by the husband and wife; their anonymity was assured. The first pages of the questionnaire required subjects to estimate the extent of their responsibility for each of 20 activities relevant to married couples by putting a slash through a $150-\mathrm{mm}$ straight line, the endpoints of which were labeled "primarily wife" and "primarily husband." 1 The twenty activities were making breakfast, cleaning dishes, cleaning house, shopping for groceries, caring for your children, planning joint leisure activities, deciding how money should be spent, deciding where to live, choosing friends, making important decisions that affect the two of you, causing arguments that occur between the two of you, resolving conflicts that occur between the two of you, making the house messy, washing the clothes, keeping in touch with relatives, demonstrating affection for spouse, taking out the garbage, irritating spouse, waiting for spouse, deciding whether to have children.

Subjects were next asked to record briefly examples of the contributions they or their spouses made to each activity. Their written records were subsequently examined to assess if the person's own inputs were generally more "available." That is, did the examples reported by subjects tend to focus more on their. own behaviors than on their spouses'? A rater, blind to the experimental hypothesis, recorded the number of discrete examples subjects provided of their own and of their spouses' contributions. A second rater coded one third of the data; the reliability (Pearson product-moment correlation) was .81 .

\section{Results}

The responses of both spouses to each of the responsibility questions were summed,

\footnotetext{
1 In the preliminary interviews, we used percentage estimates. We found that subjects were able to remember the percentages they recorded and that postquestionnaire comparisons of percentages provided a strong source of conflict between the spouses. The use of the $150-\mathrm{mm}$ scales circumvented these difficulties; subjects were not inclined to convert their slashes into exact percentages that could then be disputed.
} 
so that the total included the amount that the wife viewed as her contribution and the amount that the husband viewed as his contribution. Since the response scale was 150 $\mathrm{mm}$ long, there were 150 "units of responsibility" to be allocated. A sum of greater than 150 would indicate an egocentric bias in perceived contribution, in that at least one of the spouses was overestimating his or her responsibility for that activity. To assess the degree of over- or underestimation that spouses revealed for each activity, 150 was subtracted from each couple's total. A composite score was derived for the couple, averaging over the 20 activities (or 19, when the couple had no children).

An analysis of variance, using the couple as the unit of analysis, revealed that the composite scores were significantly greater than zero, $M=4.67, F(1,35)=12.89, p$ $<.001$, indicating an egocentric bias in perceived contributions. Twenty-seven of the 37 couples showed some degree of overestimation $(p<.025$, sign test). Moreover, on the average, overestimation occurred on 16 of the 20 items on the questionnaire, including negative items-for example, causing arguments that occur between the two of you, $F(1,32)$ $=20.38, p<.001$. Although the magnitude of the overestimation was relatively small, on the average, note that subjects tended to use a restricted range of the scale. Most responses were slightly above or slightly below the halfway mark on the scale. None of the items showed a significant underestimation effect.

The second set of items on the questionnaire required subjects to record examples of their own and of their spouses' contributions to each activity. A mean difference score was obtained over the 20 activities (averaging over husband and wife), with the number of examples of spouses' contributions subtracted from the number of examples of own contributions. A test of the grand mean was highly significant, $F(1,35)=36.0, p$ $<.001$; as expected, subjects provided more examples of their own $(M=10.9$ ) than of their spouses' $(M=8.1)$ inputs. The correlation between this self-other difference score and the initial measure of perceived responsibility was determined. As hypothesized, the greater the tendency to recall selfrelevant behaviors, the greater was the overestimation in perceived responsibility, $r(35)$ $=.50, p<.01$.

The number of words contained in each behavioral example reported by the subjects was also assessed to provide a measure of elaboration or richness of recall. The mean number of words per example did not differ as a function of whether the behavior was reported to be emitted by self $(M=10.0)$ or spouse $(M=10.1), F<1$. Further, this measure was uncorrelated with the measure of perceived responsibility, $r(35)=-.15, n s$.

In summary, both the measure of responsibility and the measure reflecting the availability of relevant behaviors showed the hypothesized egocentric biases. Moreover, there was a significant correlation between the magnitude of the bias in availability and the magnitude of the bias in responsibility. This finding is consistent with the hypothesis that egocentric biases in attributions of responsibility are mediated by biases in availability. Finally, the amount of behavior recalled seemed to be the important factor, rather than the richness of the recall.

\section{Experiment 2}

The data from Experiment 1 indicate that egocentric biases in availability and attributions of responsibility occur in ongoing relationships. The remaining experiments were designed to demonstrate the prevalence of these phenomena, and to investigate some of the factors that were expected to influence their magnitude.

The major purpose of Experiment 2 was to evaluate the self-esteem interpretation of the availability bias. If the availability bias is caused primarily by the motivation to enhance self-esteem, recall of a joint endeavor should facilitate an acceptance of personal responsibility after success and a denial of personal responsibility after failure. Consequently, the self-esteem interpretation implies that self-generated inputs should be more available after success than after failure. The evidence from past research that 
people accept more responsibility for a success than for a failure is consistent with this reasoning (e.g., Luginbuhl, Crowe, \& Kahan, 1975; Sicoly \& Ross, 1977; Wortman, Costanzo, \& Witt, 1973).

In Experiment 2, subjects learned several days after participating in a problem-solving task that their group had performed either well or poorly. It was hypothesized that subjects would recall a greater proportion of their own statements when the group product was positively evaluated. Because we moved to the laboratory for this experiment, it was possible to tape record the group's initial interaction. This recording provided a "reality base" against which to compare the subsequent recall of subjects.

\section{Method}

\section{Subjects}

The subjects were 37 males and 7 females selected from lists of students living at the university. Subjects were paid $\$ 5$ each. All of the subjects participated in both sessions.

\section{Procedure}

The experiment was conducted in two sessions separated by a 3- or 4-day interval. Subjects reported for the first session in groups of two. They were told that the purpose of the study was to determine whether groups exhibit more social awareness than individuals. They were given 10 minutes to read a case study of Paula, a psychologically troubled person (selected from Goldstein \& Palmer, 1975). Each subject in the dyad was provided with different portions of the case study. The subjects were next asked questions designed to assess their psychological understanding of Paula's difficulties. They were told to discuss each question and arrive at a joint response, taking into account the different information that each group member brought with him or her to the case. Subjects were told that their discussions were being tape recorded. The experimenter informed them that she would listen to the tapes following the session to evaluate the group's answers.

Subjects returned individually for the second session. In a random one half of the dyads, subjects were led to believe that their group had performed poorly relative to other groups in the experiment (third from the worst). In the remaining dyads, subjects were informed that their group had performed relatively well (third from the best). Subjects were then told, "Write down as much as you can recall of your group's discussion of Paula. You will only have a short time to do this, so it is unlikely that you will be able to report all or even most of what was said. It is, therefore, important that you put things down in the order that they come to you. . . . If you remember the idea, but not the exact comment, rephrase it in your own words." Subjects were told not to record who said each statement. They were simply to write what was said.

Subjects were asked to stop writing at the end of 8 minutes and to go back over their responses to indicate who said each statement during the discussion. Finally, they were asked whether, in their opinion, each statement improved or lowered their group's score, or whether they were uncertain. Subjects were debriefed at the end of the second session.

An observer who was blind to the subjects' treatment conditions contrasted subjects' recall with their original comments on the tape to assess accuracy. A statement was judged to be accurate if it represented an idea that the subject expressed during the interaction, even though the actual words used during the discussion might have differed from the words recalled by the subject. A second rater scored a random one third of the tapes, and agreement was $93 \%$.

\section{Results and Discussion}

\section{Availability}

The proportion of statements that subjects attributed to themselves was calculated for each member of the dyad. The average proportion for each dyad served as the unit of analysis. In 21 of the 22 dyads, the subjects attributed the majority of the statements that they recalled to themselves $(p<.001$, sign test). The average proportion of subjects' own statements was .70 in the success condition and .60 in the failure condition. Each of these proportions was significantly greater than a .50 or chance expectancy, $t(10)=9.09, p<.001$, and $t(10)=3.22, p$ $<.01$, respectively. Thus, in both the success and failure conditions, subjects attributed significantly more of the recalled statements to themselves than would be expected by chance. Nevertheless, as hypothesized, subjects attributed a greater proportion of the recalled statements to themselves after a success than after a failure, $F(1,20)=7.10$, $p<.025$. The total number of statements recalled (adding over statements attributed to self and the other person) did not differ 
significantly as a function of the group's performance $(F=1.57)$.

\section{Accuracy}

Subjects' recall was compared with the taped record in a $2 \times 2$ between-within anal$y$ ysis of variance (Success vs. Failure $\times$ Self vs. Partner), with the dyad as the unit of analysis. Subjects recalled a higher percentage of their own actual statements ( $M=$ $5.6 \%$ ) than of their partner's actual statements $(M=2.6 \%), F(1,19)=18.37, p<$ $.001 .^{2}$ Although the means seem low, note that subjects were given only an 8-minute recall period. The group's performance level did not affect the percentage of actual statements recalled (main effect and interaction $F_{\mathrm{S}}<1$ ).

We also compared the accuracy of the statements subjects attributed to themselves with the accuracy of the statements they attributed to their partners. Sixty-nine percent of the statements that subjects attributed to self were accurate reflections of self-generated comments; $56 \%$ of the statements that subjects attributed to their partners were accurate. The difference between these two percentages was significant, $F(1,19)=$ $7.06, p<.025$. The group's performance level did not significantly affect the accuracy of the attributed statements (success-fail main effect $F=1.14$, interaction $F<1$ ).

Most of the errors that subjects made were of two types: They recalled material from the case history that had not been mentioned in the discussion; they reported inferences and conclusions that were not contained in the case history or in the discussion. In only a few instances (approximately $2 \%$ of the errors) did subjects take credit for statements made by their partners.

\section{Evaluations}

Finally, subjects' evaluations of the statements were transcribed onto a 3-point scale: +1 (improved the group's score), 0 (uncertain), and -1 (lowered the group's score). Two scores were obtained for each subject: the average rating of comments attributed to self and the average rating of statements attributed to the other person. An analysis of variance, with the dyad as the unit of analysis, revealed a main effect for success-fail, $F(1,20)=14.56, p<.005$, and a SuccessFail $\times$ Self-Other interaction, $F(1,20)=$ $5.19, p<.05$.

The success-fail main effect indicated that statements were evaluated more positively following success $(M=.75)$ than following failure $(M=.41)$. The interaction revealed that whereas subjects' evaluations of their own comments were marginally lower in the failure condition than in the success condition ( $M$ difference $=.18, t=1.85, p<.10$ ), their evaluations of the other person's comments were significantly lower in the failure condition than in the success condition ( $M$ difference $=.50, t=5.14, p<.01$ )

In summary, the present study provided some evidence for the self-esteem maintenance hypothesis. Subjects attributed a higher proportion of the recalled comments to themselves after success than after failure; subjects' evaluations of the recalled statements suggested an attempt to shift the blame for failure onto their partners. On the other hand, contrary to the self-esteem interpretation, recall was egocentric even in the failure condition.

Note that the strong egocentricity obtained on the recall measure and the increased accuracy of self-generated statements may reflect, in part, the fact that subjects initially read different aspects of the case history. Since they subsequently presented this material to the other person in responding to the questions, subjects' own contributions may have received more "study time." Nevertheless, this differential is ecologically valid. A person's inputs are often derived from his or her previous history and experiences.

\section{Experiment 3}

In Experiment 3 we examined the effects of success and failure in a more natural setting. We had the players on 12 intercollegiate basketball teams individually complete a

2 The tapes from one of the failure groups were lost; this group is omitted from the analysis. 
questionnaire in which they were asked to recall an important turning point in their last game and to assess why their team had won or lost.

It is a leap to go from the self-other comparisons that we have considered in the previous studies to own team - other team comparisons. There are, however, a number of reasons to expect that the actions of one's own team should be more available to the attributor than the actions of the other team: I know the names of my teammates, and therefore, $I$ have a ready means of organizing the storage and retrieval of data relevant to them; our success in future games against other opponents depends more on our own offensive and defensive abilities than on the abilities of the opposing team. Consequently, I may attend more closely to the actions of my teammates, which would enhance encoding and storage. Also, there are informational disparities: The strategies of my own team are more salient than are the strategies of the opposing team (Tversky \& Kahneman, 1973).

If the initiatives of one's own team are differentially available, players should recall a turning point in terms of the actions of their team and attribute responsibility for the game outcome to their team. On the basis of the data from Experiment 2, it may be expected that these tendencies will be stronger after a win than after a loss.

\section{Method}

\section{Subjects}

Seventy-four female and 84 male intercollegiate basketball players participated in the study. The team managers were contacted by telephone; all agreed, following discussions with their players, to have their teams participate in the study.

\section{Procedure}

The questionnaires were administered after six games in which the teams participating in the study played each other. Thus, for the three male games chosen, three of the six male teams in the study were competing against the other three male teams. Similarly, the three female games selected included all six of the female teams. The questionnaires were administered at the first team practice following the target game ( 1 or 2 days after the game), except in one case where, because of the teams' schedules of play, it was necessary to collect data immediately after the game (two female teams). The questionnaires were completed individually, and the respondents' anonymity was assured. The relevant questions, from the current perspective, were the following:

1. Please describe briefly one important turning point in the last game and indicate in which period it occurred.

2. Our team won/lost our last game because. ...

The responses to the first question were examined to determine if the turning point was described as precipitated by one's own team, both teams, or the other team. Responses to the second question were examined to assess the number of reasons for the win or loss that related to the actions of either one's own or the opposing team. The data were coded by a person who was unaware of the experimental hypotheses. A second observer independently coded the responses from $50 \%$ of the subjects. There was $100 \%$ agreement for both questions.

\section{Results}

There were no significant sex differences on the two dependent measures; the results are, therefore, reported collapsed across gender. Since team members' responses cannot be viewed as independent, responses were averaged, and the team served as the unit of analysis.

A preliminary examination of the "turning point" data revealed that even within a team, the players were recalling quite different events. Nevertheless, 119 players recalled a turning point that they described as precipitated by the actions of their own team; 13 players recalled a turning point that they viewed as caused by both teams; 16 players recalled a turning point seen to be initiated by the actions of the opposing team (the remaining 10 players did not answer the question). Subjects described such events as a strong defense during the last 2 minutes of the game, a defensive steal, a shift in offensive strategies, and so on.

The percentage of players who recalled a turning point caused by their teammates was derived for each team. These 12 scores were submitted to an analysis that compared them to a chance expectancy of $50 \%$. The obtained distribution was significantly different from chance, $F(1,11)=30.25, p<.001$, with a mean of $80.25 \%$. As hypothesized, 
most reports emphasized the actions of the players' own team.

The percentage of players who recalled a turning point caused by their teammates was examined in relation to the team's performance. The average percentage was higher on the losing team than on the winning team in five of the six games $(p<.11$, sign test). The mean difference between the percentages on losing ( $M=88.5)$ and winning ( $M=$ 72.) teams was nonsignificant $(F<1)$.

The players' explanations for their team's win or loss were also examined. Of the 158 participants, only 14 provided any reasons that involved the actions of the opposing team. On the average, subjects reported 1.79 reasons for the win or loss that involved their own team and .09 reasons that involved the opposing team, $F(1,11)=272.91, p<.001$. Finally, the tendency to ascribe more reasons to one's own team was nonsignificantly greater after a loss $(M=1.73)$ than after a win $(M=1.65), F<1$.

\section{Discussion}

The responses to the turning point question indicate that the performances of subjects' teammates were more available than those of opposing team members. Further, subjects ascribed responsibility for the game outcome to the actions or inactions of their teammates rather than to those of members of the opposing team. Thus, biases in availability and judgments of responsibility can occur at the group level. Rather and Heskowitz (1977) provide another example of group egocentrism: "CBS (news) became a solid Number One after the Apollo moonshot in 1968. If you are a CBS person, you tend to say our coverage of the lunar landing tipped us over. If you are a NBC person, you tend to cite the break-up of the HuntleyBrinkley team as the key factor" (p. 307).

Contrary to the data from Experiment 2, the availability bias in Experiment 3 was as strong after failure as after success. There are differences between the studies that may contribute to this discrepancy. The "egocentric" availability and attributions in the basketball experiment were team rather than self-oriented; as a result, responsibility for failure was more diffused, and subjects' selfesteem was threatened less directly. Also, unlike the group in the laboratory study, the basketball team had a future: The players could enhance their control over subsequent game outcomes by locating causality within their own team. Finally, and perhaps most important, unlike the laboratory group, the team also had a past. Team members recalled aspects of their behavior that changed and attributed the game outcomes to these variations (e.g., we win because of discipline and hustle; we lose because of a lack of discipline and hustle). What players seemed to ignore, however, was that the opposing teams might contribute to these fluctuations.

It seems likely that a tendency to perceive both teams as responsible for the game outcome might increase with the magnitude of the win or loss (assuming that large wins or losses are atypical). As Kelley (1973) noted, multiple causes are necessary to explain extreme outcomes. Although no such tendency was observed in the current study, there were too few data points (games) to provide an accurate determination.

\section{Experiment 4}

In the final two experiments, we examined the hypothesized relation between the bias in availability and the bias in attributions of responsibility more directly by introducing manipulations that should affect availability and measuring changes in attribution. In Experiment 4, subjects were required to record either their own comments (self-focus condition) or those of the other person (partner-focus condition) during a problem-solving session. At a second session, subjects were shown their notes and asked to assess the extent to which either they or their partners had been responsible for various aspects of the decision-making process. It was assumed that the partner-focus condition would enhance encoding and retrieval of the partner's contributions. Thus, the partner's inputs would be more available when assessments of responsibility were made, and subjects should assign their partner more responsi- 
bility for group decision-making in the partner-focus condition than in the self-focus condition.

\section{Method}

\section{Subjects}

The subjects were 40 males recruited from the introductory psychology subject pool.

\section{Procedure}

Subjects were scheduled in pairs for the first session. In a few introductory comments, the experimenter described the difficulty of preventing people from smoking. Subjects were then told they were participating in a pilot project to assess the efficacy of "brainstorming techniques" as a means of providing possible solutions to this problem. They were further informed that solutions generated during their discussion would be sent to the Committee for the Prevention of Cigarette Smoking (a government committee). Subjects were told to follow a four-step sequence: define the problem, generate as many solutions as possible, discuss the pros and cons of each proposed solution, and finally, select a preferred solution and explain the reasons for this choice.

Subjects in the self-focus condition were asked to keep a record of their own contributions to the discussion. Subjects in the partner-focus condition were asked to keep a record of only the other person's inputs: "This will leave you free to think and develop your ideas because your partner will be doing the writing." Subjects were given about 45 minutes for discussion.

Subjects returned individually for a second session 2-3 days later. Each subject was asked to look over the notes he had taken during the previous session, "in order to refresh your recollection of the discussion."

Subjects completed the dependent measures after they had reviewed their notes of Session 1. The principal dependent variable required subjects to indicate who tended to control the course and content of the discussion during the first session. They were asked to assess this overall, and also with respect to the various stages of the discussion, on $150-\mathrm{mm}$ scales with endpoints labeled "the other person" and "me."

\section{Results}

A $2 \times 2$ analysis of variance was performed on the data. Self- versus partner focus was a between-subjects factor. Since the dyad was treated as an experimental unit, the response made by each member of the pair was considered to be a repeated measure.
The focus manipulation had no reliable impact on attributions of responsibility (all $F_{\mathrm{S}}<1$ ). Once again, however, there was strong evidence of an egocentric bias in allocations of responsibility. Subjects reported that they had exerted more control over the course and content of each segment of the discussion than their partners ascribed to them-solutions stage: 85 versus $68, F(1,18)$ $=7.32, p<.025$; evaluation stage: 79 versus $70, F(1,18)=4.13, p<.07$; final proposal stage: 86 versus $67, F(1,18)=11.31$, $p<.01$; overall discussion: 89 versus 72 , $F(1,18)=9.21, p<.01$. Note that for each item, A's self-attributions were, on the average, beyond the midpoint of the $150-\mathrm{mm}$ scale, indicating a perceived contribution of greater than $50 \%$; on the other hand, the partner viewed A's contributions as being less than 50\% in each instance.

\section{Discussion}

The results revealed strong egocentric biases in individuals' attributions of responsibility for segments of the problem-solving task. The focus manipulation had surprisingly little effect, however. What we had viewed to be a sledgehammer manipulation turned out to be ineffective.

Why did the attention manipulation have so little impact? One possibility is that subjects may have found the written records to be relatively uninformative and relied more on their memories than on the notes in responding to the questionnaire (hence, the strong egocentric biases). The notes may have appeared inadequate, in part because they were very brief, usually about one page, relative to the length of the interaction (45 minutes). Moreover, much of what subjects wrote may have seemed irrelevant to the final decisions made by the group. In short, we may not have succeeded in focusing subjects' attention on what, from their perspective, were the important aspects of the interaction. To obtain this information they were, perhaps, only too willing to rely on their memories.

Finally, note that recent research on the relation between attention and recall in interpersonal perception settings has yielded 
inconsistent results (Taylor \& Fiske, 1978). This situation stands in marked contrast to the strong relation evident in the cognitive literature (Cofer, 1977; Loftus \& Loftus, 1976). Unlike the constrained experimental settings utilized in cognitive research, however, the present study and those reviewed by Taylor and Fiske incorporate rich social environments. Consequently, the manipulation of attention is relatively gross; it is less certain that the individual is attending to those aspects of the situation that are relevant to the dependent measures.

\section{Experiment 5}

In Experiment 5, we again attempted to vary the individual's focus of attention so as to affect availability. In this experiment, however, we employed a manipulation designed to promote selective retrieval of information directly relevant to attributions of responsibility.

In our initial analysis, we suggested that egocentric attributions of responsibility could be produced by the selective retrieval of information from memory and that retrieval might be guided by the kinds of questions that individuals ask themselves. Experiment 5 was conducted to test this hypothesis. Subjects were induced to engage in differing retrieval by variations in the form in which questions were posed. Graduate students were stimulated to think about either their own contributions to their BA theses or the contributions of their supervisors. The amount of responsibility for the thesis that subjects allocated to either self or supervisor was then assessed. It was hypothesized that subjects would accept less responsibility for the research effort in the supervisor-focus than in the self-focus condition.

\section{Method}

\section{Subjects}

The subjects were 17 female and 12 male psychology graduate students. Most had completed either 1 or 2 years of graduate school. All of these students had conducted experiments that served as their BA theses in their final undergraduate year.

\section{Procedure}

The subjects were approached individually in their offices and asked to complete a brief questionnaire on supervisor-student relations. None refused to participate. The two forms of the questionnaire were randomly distributed to the subjects; they were assured that their responses would be anonymous and confidential.

One form of the questionnaire asked the subjects to indicate their own contribution to each of a number of activities related to their BA theses. The questions were as follows: (a) "I suggested percent of the methodology that was finally employed in the study." (b) "I provided — percent of the interpretation of results." (c) "I initiated percent of the thesis-relevant discussions with my supervisor." (d) "During thesis-related discussions I tended to control the course and content of the discussion ___ percent of the time. (e) "All things considered, I was responsible for ___ percent of the entire research effort." (f) "How would you evaluate your thesis relative to others done in the department?"

The second form of the questionnaire was identical to the above, except that the word $I$ (self-focus condition) was replaced with my supervisor (supervisor-focus condition) on Questions 1-5. Subjects were asked to fill in the blanks in response to the first five questions and to put a slash through a 150-mm line, with endpoints labeled "inferior" and "superior," in response to Question 6.

\section{Results and Discussion}

For purposes of the analyses, it was assumed that the supervisor's and the student's contribution to each item would add up to $100 \%$. Though the experiment was introduced as a study of supervisor-student relations, it is possible that the students may have considered in their estimates the inputs of other individuals (e.g., fellow students). Nevertheless, the current procedure provides a conservative test of the experimental hypothesis. For example, if a subject responded $20 \%$ to an item in the "I" version of the questionnaire, it was assumed that his or her supervisor contributed $80 \%$. Yet the supervisor may have contributed only $60 \%$, with an unspecified person providing the remainder. By possibly overestimating the supervisor's contribution, however, we are biasing the data against the experimental hypothesis: The "I" version was expected to reduce the percentage of responsibility allocated to the supervisor. 
Subjects' responses to the first five questions on the "I" form of the questionnaire were subtracted from 100 , so that higher numbers would reflect greater contributions by the supervisor in both conditions. Question 5 dealt with overall responsibility for the research effort. As anticipated, subjects allocated more responsibility to the supervisor in the supervisor-focus $(M=33.3 \%)$ than in the self-focus $(M=16.5 \%)$ condition, $F(1$, 27) $=9.05, p<.01$. The first four questions were concerned with different aspects of the thesis, and the average response revealed a similar result: supervisor-focus $M=33.34$; self-focus $M=21.82 ; F(1,27)=5.34, p<$ .05 . Finally, subjects tended to evaluate their thesis more positively in the self-focus condition than in the supervisor-focus condition: 112.6 versus $94.6, F(1,27)=3.59, p<.10$.

The contrasting wording of the questions had the anticipated impact on subjects' allocations of responsibility. The supervisor version of the questionnaire presumably caused subjects to recall a greater proportion of their supervisors' contributions than did the "I" form of the questionnaire. This differential availability was then reflected in the allocations of responsibility. Note, however, that the questions were not entirely successful in controlling subjects' retrieval. The supervisor was allocated only one third of the responsibility for the thesis in the supervisor-focus condition.

In light of the present data, the basketball players' attributions of responsibility for the game outcome in Experiment 3 need to be reexamined. Recall that the players were asked to complete the sentence, "Our team won/lost our last game because. . .." This question yielded a highly significant egocentric bias. With hindsight, it is evident that the form of the question-"Our team .. . our last game" - may have prompted subjects to focus on the actions of their own teams, even though the wording does not preclude references to the opposing team. The "turning point" question in Experiment 3 was more neutrally worded and is not susceptible to this alternative interpretation.

The leading questions in these studies emanate from an external source; many of our retrieval queries are self-initiated, however, and our recall may well be biased by the form in which we pose retrieval questions to ourselves. For example, basketball players are probably more likely to think in terms of "Why did we win or lose?" than in terms of a neutrally phrased "Which team was responsible for the game outcome?"

\section{General Discussion}

The five studies employed different subject populations, tasks, and dependent measures. As hypothesized, the egocentric biases in availability and attribution appear to be robust and pervasive.

\section{Determinants of the Availability Bias}

Several processes were hypothesized to contribute to the increased availability of self-generated inputs. It is possible to consider how well each accounts for the existing data. Selective encoding and storage cannot have contributed to the effects of success versus failure on availability in Experiment 2 or of supervisor- versus self-focus in Experiment 5 (since these manipulations occurred long after encoding and storage took place). Informational disparities should not have contributed to the pretest results (subjects' time estimates were based solely on the preceding discussion), to the tendency to attribute a higher proportion of the recalled statements to oneself in the success as compared to the failure condition in Experiment 2 , or to the effects of supervisor- versus selffocus in Experiment 5 (since neither performance level, as operationalized here, nor focus could affect the information initially available to the subjects). Two motivational processes were posited. Self-esteem maintenance does not seem pertinent to the results obtained from the two-person groups in the pretest. Nor does it account for (a) the overrecall of self-generated inputs in the failure condition of Experiment 2 and (b) the finding that players on losing basketball teams recalled the turning point of the game in terms of the actions of their teammates. The control motivation hypothesis fares somewhat better. Although focusing on one's own inputs in failure situations may lower self-esteem, it 
does permit one to perceive personal control over the activity. Hence, efficacy motivation could account for these results. Nevertheless, a desire for personal efficacy does not appear to explain all of the data. The two-person groups in the pretest seem to reveal a relatively "pure" information-processing effect: It is unlikely that people would feel a need to report that they dominated casual conversations. Also, the effect of supervisor- versus self-focus in Experiment 5 appears to be mediated by differential retrieval. Efficacy considerations may have induced the subjects to report that they were major contributors to their theses; nonetheless, motivational concerns do not dictate that focusing on the supervisor's contributions will reduce one's need to assume responsibility.

In summary, selective encoding and storage, informational disparities, and motivational influences do not appear to be necessary determinants of the egocentric bias in availability. The one remaining process that was posited, selective retrieval, is not precluded by any of the current data; further, it receives direct support from the findings in Experiments 2 and 5.

Nevertheless, it seems premature to eliminate any of the hypothesized processes as sufficient causes of the availability bias. The tendency of spouses to recall their own contributions in Experiment 1 may reflect informational disparities; the desire to maintain self-esteem may have contributed to the effect of performance level in Experiment 2; basketball players' responses to the turning point question in Experiment 3 may well have been influenced by selective encoding and by control motivation.

We suspect that, like many cognitive phenomena (cf. Erdelyi, 1974; Erdelyi \& Goldberg, in press; McGuire, 1973), biases in availability are multidetermined in real life. Multidetermination may seem an unsatisfying resolution; however, it is one that social psychologists shall probably confront increasingly as they begin to study cognitive phenomena in situ. Researchers in other sciences face parallel complexities. For example, similar cancers appear to have different etiologies, depending, among other factors, on the environment in which the patient lives (Goodfield, 1976).

\section{The Link Between Availability and Attributions of Responsibility}

The focus of the present research has been on demonstrating that the hypothesized biases in availability and attribution exist and are relatively ubiquitous. It was also hypothesized, however, that the egocentric bias in attributions of responsibility would be mediated by the bias in availability. Although the data are suggestive, we have no definitive evidence that the bias in availability causes the bias in responsibility. The strongest affirmative evidence is that the two biases were significantly correlated in the marriage study and that a manipulation designed to induce selective retrieval influenced attributions of responsibility (Experiment 5). In opposition, it might be contended that the covariation between the two biases is susceptible to a number of alternative causal interpretations and that there is no direct evidence that the retrieval manipulation in Experiment 5 affected availability. Conceivably, the attributions of responsibility in Experiment 5 were mediated by some other factor not yet identified. Further evidence will be required to establish whether the bias in responsibility is caused by the bias in availability. The present results suggest several additional considerations, however, concerning the determinants and pervasiveness of the biases.

\section{Pervasiveness of the Egocentric Biases}

The egocentric biases obtained in the current studies may seem inconsistent with Jones and Nisbett's (1971) proposal that actors locate causality for their actions primarily within their environment. There are a number of differences between the two paradigms that might account for the discrepancy. Most important, Jones and Nisbett were concerned with interpretation, whereas we focused on recall and judgments of responsibility. Actors could presumably overestimate their contributions to a joint product and, at the same time, locate the cause of their behavior with- 
in the environment. For example, suppose that a wife who reports that she does $80 \%$ of the cleaning is asked why she cleans (the central question for Jones and Nisbett). She may respond that the house is dirty, an environmental attribution. Conversely, her husband, who perhaps accepts $30 \%$ of the responsibility for cleaning, may answer the same question by pointing out that his wife has a fetish for cleanliness, a trait attribution.

Thus, the current data do not speak directly to the Jones and Nisbett hypothesis. Nevertheless, our data do seem to contradict related evidence that the responses of actors are more salient and available to observers than to actors themselves (Storms, 1973; Taylor \& Fiske, 1975). The critical variable may be the extent to which the observer departs from a passive role and interacts with the actor. When, as in the present research, individuals undertake complex social interactions, they alternate between the roles of speaker (actor) and listener (observer), yet much of their attention may be directed at planning and executing their own responses. Although they do not attend to themselves perceptually, they may be cognitively selffocused; therefore, self-generated inputs are likely to be more available in recall. On the other hand, passive observers may concentrate on other persons in their environment. Also, observers may be less self-absorbed when their own responses require little attention, as, for example, when they enact well-practiced behaviors (Langer, 1978, has speculated that a wide range of social behaviors require minimal thought).

These instances notwithstanding, the present research demonstrates the prevalence of self-centered biases in availability and judgments of responsibility. In everyday life, these egocentric tendencies may be overlooked when joint endeavors do not require explicit allocations of responsibility. If allocations are stated distinctly, however, there is a potential for dissension, and individuals are unlikely to realize that their differences in judgment could arise from honest evaluations of information that is differentially available.

\section{Reference Note}

1. Greenwald, A. G. The tolitarian ego: Fabrication and revision of personal history. Unpublished manuscript, 1978.

\section{References}

Bartlett, F. C. Remembering. Cambridge, England: Cambridge University Press, 1932.

Bruner, J. S. The act of discovery. Harvard Educational Review, 1961, 31, 21-32.

Carver, R. P. A critical review of mathagenic behaviors and the effect of questions upon the retention of prose materials. Journal of Reading Behavior, 1972, 4, 93-119.

Cofer, C. N. On the constructive theory of memory. In I. A. Uzgiris \& F. Weizmann (Eds.), The structuring of experience. New York: Plenum Press, 1977

deCharms, R. C. Personal causation: The internal affective determinants of behavior. New York: Academic Press, 1968.

Erdelyi, M. H. A new look at the new look: Perceptual defense and vigilance. Psychological Review, 1974, 81, 1-25.

Erdelyi, M. H., \& Goldberg, B. Let's not sweep repression under the rug: Towards a cognitive psychology of repression. In J. F. Kihlstrom \& F. J. Evans (Eds.), Functional disorders of memory. Hillsdale, N.J.: Erlbaum, in press.

Goldstein, M. J., \& Palmer, J. O. The experience of anxiety. New York: Oxford University Press, 1975.

Goodfield, J. The siege of cancer. New York: Dell, 1976.

Greenwald, A. G., \& Albert, R. D. Acceptance and recall of improvised arguments. Journal of Personality and Social Psychology, 1968, 8, 31-34.

Greenwald, A. G., \& Sakumura, J. S. Attitude and selective learning: Where are the phenomena of yesteryear? Journal of Personality and Social Psychology, 1967, 7, 387-397.

Jones, E. E., \& Nisbett, R. E. The actor and the observer: Divergent perceptions of the causes of behavior. Morristown, N.J.: General Learning Press, 1971.

Kelley, H. H. The process of causal attribution. American Psychologist, 1973, 28, 107-128.

Langer, E. J. Rethinking the role of thought in social interaction. In J. H. Harvey, W. J. Ickes, \& R. F. Kidd (Eds.), New directions in attribution research (Vol. 2). Potomac, Md.: Erlbaum, 1978.

Loftus, G. R., \& Loftus, E. F. Human memory: The processing of information. Hillsdale, N.J.: Erlbaum, 1976.

Luginbuhl, J. E. R., Crowe, D. H., \& Kahan, J. P. Causal attribution for success and failure. Journal of Personality and Social Psychology, 1975, 31, 86-93.

Malpass, R. S. Effects of attitude on learning and memory: The influence of instruction-induced sets. Journal of Experimental Social Psychology, 1969, $5,441-453$. 
McGuire, W. J. The yin and yang of progress in social psychology: Seven Koan. Journal of Personality and Social Psychology, 1973, 26, 446-456.

Rather, D., \& Heskowitz, M. The camera never blinks. New York: Ballantine Books, 1977.

Rogers, T. B., Kuiper, N. A., \& Kirker, W. S. Selfreference and the encoding of personal information. Journal of Personality and Social Psychology, $1977,35,677-688$.

Sicoly, F, \& Ross, M. The facilitation of egobiased attributions by means of self-serving observer feedback. Journal of Personality and Social Psychology, 1977, 35, 734-741.

Storms, M. D. Videotape and the attribution process: Reversing actors' and observers' points of view. Journal of Personality and Social Psychology, 1973, 27, 165-175.

Taylor, S. E., \& Fiske, S. T. Point of view and perceptions of causality. Journal of Personality and Social Psychology, 1975, 32, 439-445.

Taylor, S. E., \& Fiske, S. T. Salience, attention, and attribution: Top of the head phenomena. In $\mathbf{L}$. Berkowitz (Ed.), Advances in experimental social psychology (Vol. 11). New York: Academic Press, 1978.

Tversky, A, \& Kahneman, D. Availability: A heurisitc for judging frequency and probability. Cog nitive Psychology, 1973, 5, 207-232.

White, R. W. Motivation reconsidered: The concept of competence. Psychological Review, 1959, 66, 297-333.

Wortman, C. B., Costanzo, P. R., \& Witt, T. R. Effect of anticipated performance on the attribution of causality to self and others. Journal of Personality and Social Psychology, 1973, 27, 372381.

Received February 20, 1978 